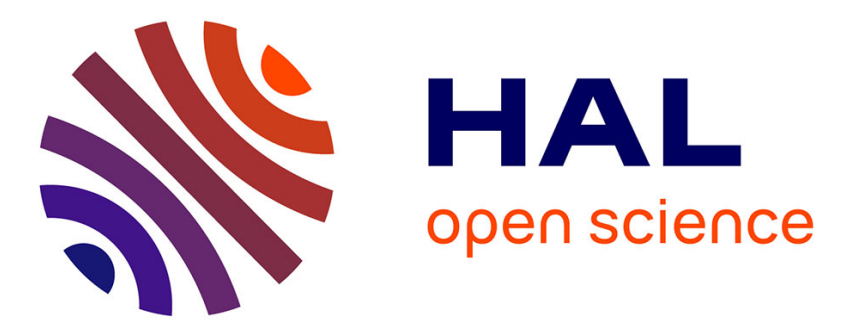

\title{
Molecular Diversity of Cyclooctatetraenes through Palladium-Catalyzed Cascade Reactions
}

Sarah Blouin, Romain Pertschi, Angèle Schoenfelder, Jean Suffert, Gaëlle Blond

\section{- To cite this version:}

Sarah Blouin, Romain Pertschi, Angèle Schoenfelder, Jean Suffert, Gaëlle Blond. Molecular Diversity of Cyclooctatetraenes through Palladium-Catalyzed Cascade Reactions. Advanced Synthesis and Catalysis, 2018, 360 (11), pp.2166-2171. 10.1002/adsc.201800110 . hal-02322480

\section{HAL Id: hal-02322480 \\ https://hal.science/hal-02322480}

Submitted on 14 Feb 2022

HAL is a multi-disciplinary open access archive for the deposit and dissemination of scientific research documents, whether they are published or not. The documents may come from teaching and research institutions in France or abroad, or from public or private research centers.
L'archive ouverte pluridisciplinaire HAL, est destinée au dépôt et à la diffusion de documents scientifiques de niveau recherche, publiés ou non, émanant des établissements d'enseignement et de recherche français ou étrangers, des laboratoires publics ou privés. 


\title{
Molecular Diversity of Cyclooctatetraenes through Palladium- Catalyzed Cascade Reactions
}

\author{
Sarah Blouin, Romain Pertschi, Angèle Schoenfelder, Jean Suffert* and Gaëlle Blond* \\ Université de Strasbourg, CNRS, LIT UMR 7200, F-67000 Strasbourg, France; Fax: (+33) 368854310 \\ Phone: (+33) 368854230; e-mail: jean.suffert@unistra.fr \\ Phone: (+33) 368854165; e-mail: gaelle.blond@unistra.fr \\ Received: ((will be filled in by the editorial staff)) \\ Supporting information for this article is available on the WWW under http://dx.doi.org/10.1002/adsc.201\#\#\#\#\#\#.((Please \\ delete if not appropriate))
}

\begin{abstract}
We report a cascade reaction leading to fully substituted cyclooctatetraenes. This transformation likely proceeds through a double cyclocarbopalladation, a unique $8 \pi$-electrocyclization and ends by either a Stille, Sonogashira or Suzuki-Miyaura cross coupling. Structural modifications of the starting material were investigated to identify their effects on the reaction and extend the structural diversity possible through this transformation.
\end{abstract}

Keywords: Cyclooctatetraenes; Cyclocarbopalladation; Stille reaction; Suzuki-Miyaura reaction; Sonogashira reaction; Electrocyclization

\section{Introduction}

Cyclooctatetraenes (COTs) display interesting properties $^{[1]}$ and are rare in Nature; only one natural product has been reported so far containing this moiety: caulerpin. ${ }^{[2]}$ The development of metalmediated syntheses to access highly substituted COTs has been investigated and their interest increased since the method described by Reppe in 1948. ${ }^{[3]}$ Nevertheless, most of them lead to symmetrically substituted COTs. ${ }^{[4]}$ A challenge in the field is the synthesis of fully substituted, unsymmetrical COTs with structural complexity. In this context, we recently reported a cascade sequence including cyclocarbopalladations ${ }^{[5]}$ that provides facile access to fully substituted COTs $\mathbf{2}$ from alkenyl bromides $\mathbf{1}$ and a stannane as coupling partner (Scheme 1). ${ }^{[6]}$ During this process, an aromatic side product $\mathbf{3}$ was also formed through an alternative competitive pathway. The proposed mechanism starts with twofold cyclocarbopalladations, first a 4-exo-dig and then a 5exo-dig, providing intermediate 4 . From 4 , an $8 \pi$ electrocyclization gives $\mathbf{5}$, then a $1,3 \pi$-allyl palladium shift takes place followed by a Stille cross coupling leading to the final COT 2 . To explain the formation of 3 , intermediate 4 may alternatively undergoes a disrotatory $6 \pi$-electrocyclization to give intermediate 6. This palladium species then is subjected to a $\beta$ carbon elimination to afford compound 3. DFT calculations are in full agreement with the observed results for this transformation. Nevertheless, in addition to the modest yields reached for the synthesis of COTs $2(18-53 \%)$, the toxicity of the stannane compounds and their difficulty in purifying residual tin from the products remain a major concern. We were looking for a greener route to form $\mathbf{2}$ with alternative functionalities by means of a cascade ending with a different type of cross-coupling reaction. Here, we report our results using either a Sonogashira or a Suzuki-Miyaura cross-coupling. Moreover some structural modifications of the starting material were investigated to identify their effects on the reaction and expand the structural diversity achievable through this reaction.

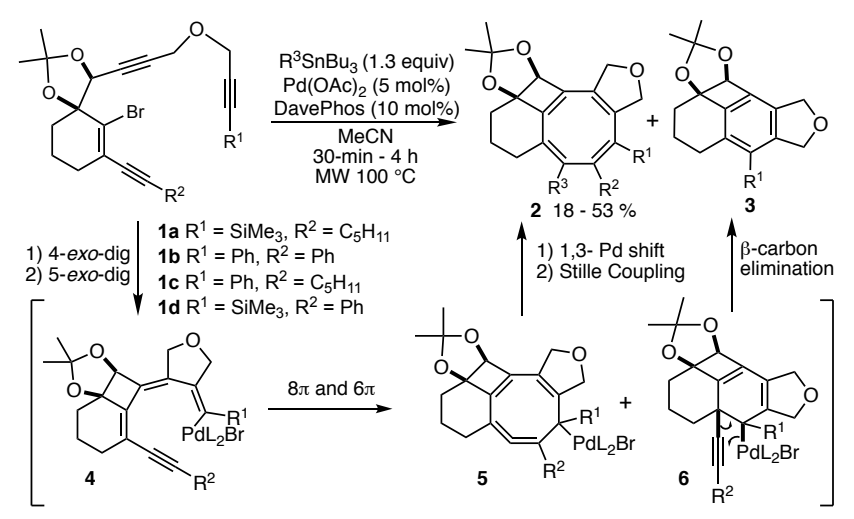

Scheme 1. Previous method and proposed mechanism.

These new approaches present major advantages: the boronic derivatives and terminal alkynes used are less toxic, completely removable and commercially available. They offer the possibility of introducing alkynyl and aryl groups with efficiencies that were not previously possible. Indeed, with the previously optimized conditions of the cascade reaction, only $18 \%$ of the COT 2 was isolated with the use of tributyl(phenylethynyl)stannane and no COT was obtained with the use of tributyl(phenyl)stannane (Scheme 2). 


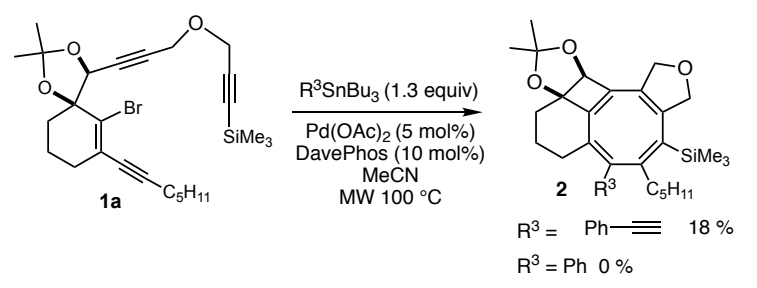

Scheme 2. Previous results with alkynyl and aryl tributylstannanes as coupling partners.

\section{Results and Discussion}

Our first objective was to terminate the cyclocarbopalladation sequence with a Sonogashira cross-coupling instead of a Stille cross-coupling to introduce alkynyl groups. This study was carried out with alkenyl bromide 1b, that worked in equivalent way in previous study. In a preliminary experiment, classical conditions for the palladium catalysis were applied using $\mathrm{Pd}(\mathrm{OAc})_{2}, \mathrm{PPh}_{3}, \mathrm{CuI}$ and trimethylsilyl acetylene as the trapping reagent of the final organopalladium species (Scheme 3). The reaction was conducted under microwave irradiation at $100{ }^{\circ} \mathrm{C}$ in diisopropylamine. After full conversion of the starting compound $\mathbf{1 b}$, COT 7 was isolated in $58 \%$ yield.

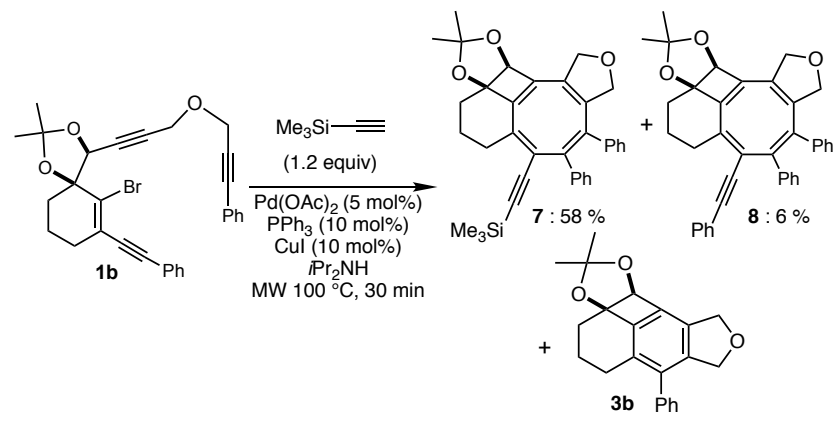

Scheme 3. Preliminary experiment.

During this process, two side products were also formed: the aromatic compound $\mathbf{3 b}$ as in the previous work and one another COT $\mathbf{8}$. The presence of $\mathbf{8}$ can be explained though the following mechanism (Scheme 4). A 4-exo-dig and a 5-exo-dig cyclocarbopalladations give intermediate 9 b. An $8 \pi-$ electrocyclization followed by a $1,3 \pi$-allyl palladium shift then takes place ended by a Sonogashira cross coupling leading to the final COT 7. To understand the formation of $\mathbf{8}$, one can suggest that the common intermediate $9 \mathbf{b}$ undergoes a $6 \pi$-electrocyclization to give intermediate 11, which leads to the aromatic compound $\mathbf{3 b}$ after a $\beta$-carbon elimination and the alkynyl palladium species 12. A transmetallation between the two-organopalladium species $\mathbf{1 0}$ and $\mathbf{1 2}$ gives intermediate $\mathbf{1 3}$, that after reductive elimination produces the new COT $\mathbf{8}$. The presence of the COT $\mathbf{8}$ also supports the proposed mechanism and confirms the formation of $\mathbf{3 b}$ occurring through a unique process of $\beta$-carbon elimination.

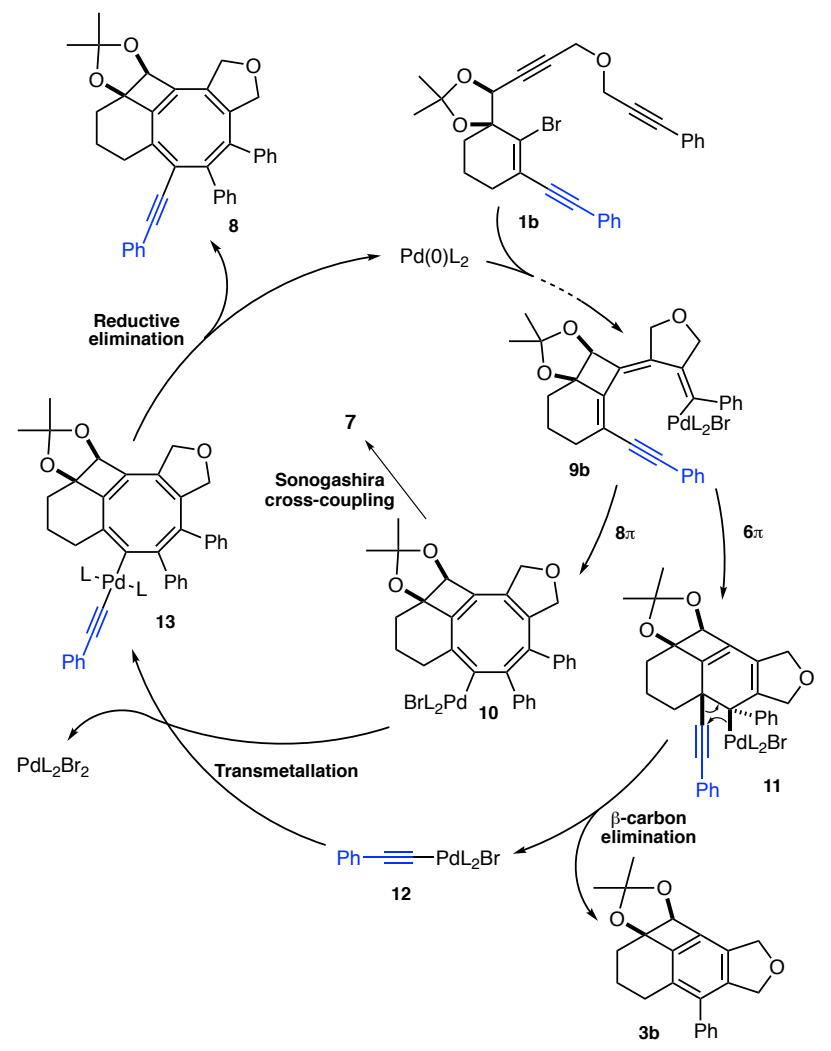

Scheme 4. Proposed mechanism.

We then decided to optimize the reaction conditions to increase the selectivity towards 7 . The reaction parameters examined were the palladium catalyst, the ligand, the copper and the base (Table 1). Side products $\mathbf{3 b}$ and $\mathbf{8}$ were observed in almost all reaction mixtures, yet they proved separable and their yield did not exceed $10-15 \%$ for both compounds. Compare to the initial reaction conditions (entry 1), the use of DavePhos, the best ligand used during the previous study, did not give good results, only $32 \%$ of COT 7 was isolated (entry 2). $\mathrm{PdCl}_{2}\left(\mathrm{PPh}_{3}\right)_{2}$ (entry 3 ) and $\mathrm{Pd}\left(\mathrm{PPh}_{3}\right)_{4}$ (entry 4) instead of the system $\mathrm{Pd}(\mathrm{OAc})_{2} / \mathrm{PPh}_{3}$ gave almost the same result. The reaction was not complete after $30 \mathrm{~min}$ with the use of diisopropylethylamine while it was the case with diisopropylamine (entry 5). With triethylamine, the reaction worked as well as in diisopropylamine $(58 \%$, entry 6). The copper source was also taken into account, and the use of $\mathrm{CuCN}$ showed identical result compared to $\mathrm{CuI}$ (entry 7). The presence of a copper source was also essential to enhance the rate of the reaction (entry 1 and 8). Eventually, the use of $\mathrm{Pd}(\mathrm{OAc})_{2} / \mathrm{PPh}_{3}$ with $\mathrm{CuI}$ in diisopropylamine or triethylamine under microwave irradiation proved to be the best conditions to obtain 7 in good yield.

Table 1. Cascade reaction ended by a Sonogashira reaction with trimethylsilyl acetylene. 


\begin{tabular}{|c|c|c|c|c|}
\hline Entry & "Pd"/Ligand & "Cu" & Solvent & Yield 7 \\
\hline 1 & $\begin{array}{l}\mathrm{Pd}(\mathrm{OAc})_{2} \\
\mathrm{PPh}_{3}\end{array}$ & $\mathrm{CuI}$ & $i \operatorname{Pr}_{2} \mathrm{NH}$ & $58 \%$ \\
\hline 2 & $\begin{array}{l}\mathrm{Pd}(\mathrm{OAc})_{2} \\
\text { DavePhos }\end{array}$ & $\mathrm{CuI}$ & $i \operatorname{Pr}_{2} \mathrm{NH}$ & $32 \%$ \\
\hline 3 & $\mathrm{Pd}(\mathrm{Cl})_{2}\left(\mathrm{PPh}_{3}\right)_{2}$ & $\mathrm{CuI}$ & $i \operatorname{Pr}_{2} \mathrm{NH}$ & $53 \%$ \\
\hline 4 & $\mathrm{Pd}\left(\mathrm{PPh}_{3}\right)_{4}$ & $\mathrm{CuI}$ & $i \operatorname{Pr}_{2} \mathrm{NH}$ & $57 \%$ \\
\hline 5 & $\begin{array}{l}\mathrm{Pd}(\mathrm{OAc})_{2} \\
\mathrm{PPh}_{3}\end{array}$ & $\mathrm{CuI}$ & $i \operatorname{Pr}_{2} \mathrm{NEt}$ & $\mathrm{nd}^{\mathrm{a})}$ \\
\hline 6 & $\begin{array}{l}\mathrm{Pd}(\mathrm{OAc})_{2} \\
\mathrm{PPh}_{3}\end{array}$ & $\mathrm{CuI}$ & $\mathrm{Et}_{3} \mathrm{~N}$ & $58 \%$ \\
\hline 7 & $\begin{array}{l}\mathrm{Pd}(\mathrm{OAc})_{2} \\
\mathrm{PPh}_{3}\end{array}$ & $\mathrm{CuCN}$ & $i \operatorname{Pr}_{2} \mathrm{NH}$ & $53 \%$ \\
\hline 8 & $\begin{array}{l}\mathrm{Pd}(\mathrm{OAc})_{2} \\
\mathrm{PPh}_{3}\end{array}$ & - & $i \operatorname{Pr}_{2} \mathrm{NH}$ & $37 \%$ b) \\
\hline
\end{tabular}

a) not determined, mostly starting material 1b. . $^{\text {) } 24 \% \text { of } \mathbf{1 b}}$ is recovered.

The scope and limitations of this reaction were next investigated. The starting compound $\mathbf{1 b}$ was tested under the optimized reaction conditions with various vinyl, silyl, aryl, alkyl acetylene $\left(\mathrm{Pd}(\mathrm{OAc})_{2}(5 \mathrm{~mol} \%)\right.$, $\mathrm{PPh}_{3}$ (10 mol\%), CuI (10 mol\%), i $\mathrm{Pr}_{2} \mathrm{NH}, \mathrm{MW}$, $100{ }^{\circ} \mathrm{C}$ ). Isolated yields for compounds $\mathbf{7 - 1 8}$ range from 50 to $71 \%$ (Scheme 5), which can be considered as good for the formation of four new C-C bonds in a one-pot operation. No reaction was observed with the use of 3,3-diethoxyprop-1-yne. Moreover, degradation of the reaction mixture was observed with the use of substrate 1e and trimethylsilyl acetylene.

To introduce an aryl group on the structure, which was not possible with the previous method (scheme 2), we suggested a new sequence and decided to use SuzukiMiyaura cross-coupling reaction conditions with 4methoxyphenylboronic acid as the coupling partner. To optimize the reaction conditions, different parameters were again tested: the palladium catalyst, the ligand, the base and the solvent mixture (Table 2). The base first was varied since it plays an important role in the mechanism of a Suzuki-Miyaura crosscoupling. ${ }^{[7]}$ In the presence of $\mathrm{Na}_{2} \mathrm{CO}_{3}$ or $\mathrm{K}_{3} \mathrm{PO}_{4}$, the reaction was not complete even after $2 \mathrm{~h}$. With $\mathrm{Cs}_{2} \mathrm{CO}_{3}$, the reaction was complete but the yield was modest, around $30 \%$. The proportion of water in THF has no effect $\left(\mathrm{THF} / \mathrm{H}_{2} \mathrm{O}: 98 / 2\right.$ and $85 / 15$, entries 1 and 2).

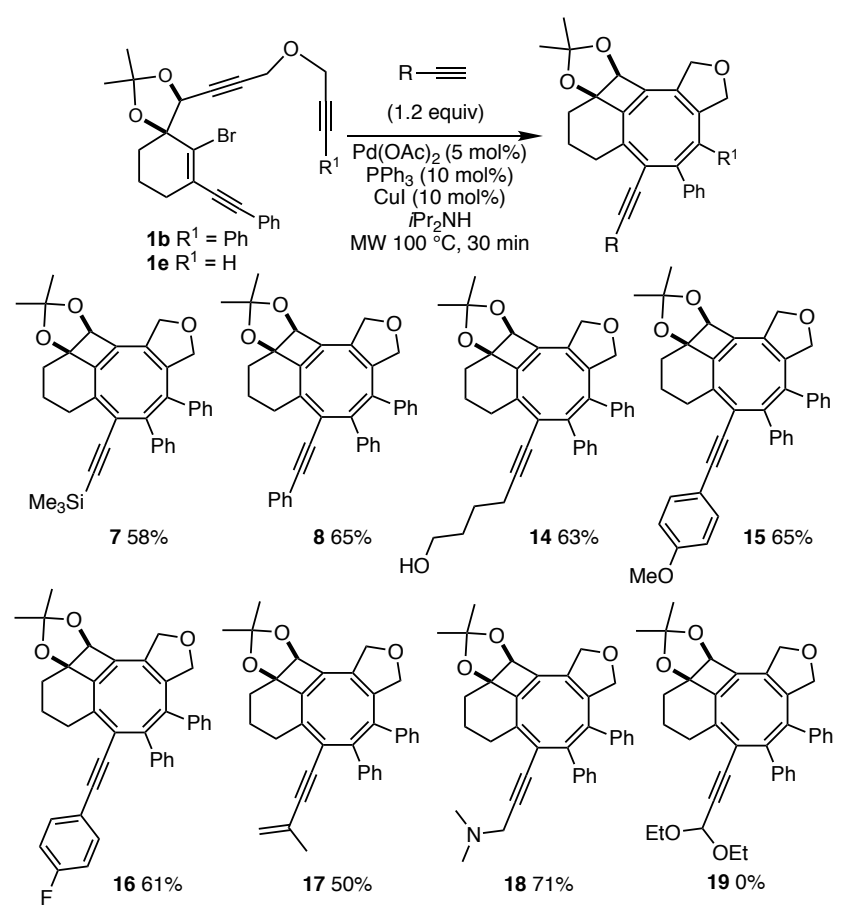

Scheme 5. Scope of the cascade reaction ended by a Sonogashira reaction.

Table 2. Cascade reaction ended by a Suzuki-Miyaura reaction with 4-methoxyphenylboronic acid. ${ }^{\text {a) }}$

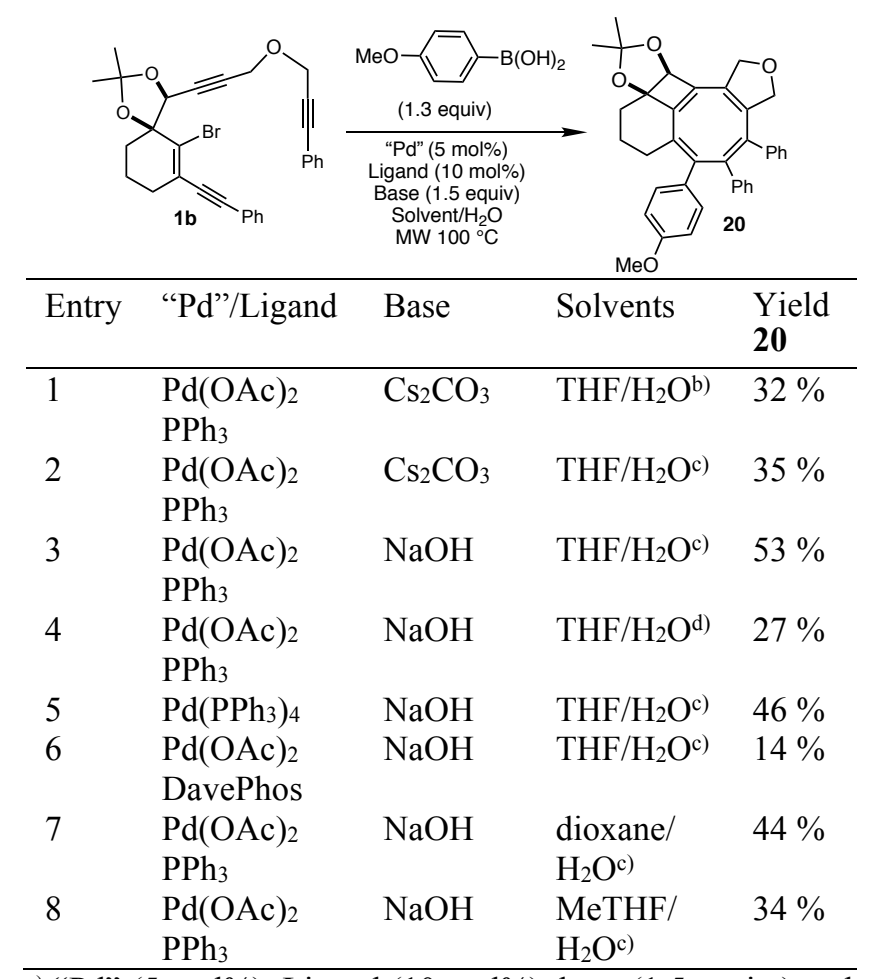

a) "Pd" (5 mol\%), Ligand (10 mol\%), base (1.5 equiv.) and 4-methoxyphenylboronic acid (1.3 equiv), solvent (0.1 M) $/ \mathrm{H}_{2} \mathrm{O}$, MW $100^{\circ} \mathrm{C}$. b) Solvent $/ \mathrm{H}_{2} \mathrm{O}$ : $98 / 2$. ${ }^{\text {c) }}$ Solvent $/ \mathrm{H}_{2} \mathrm{O}$ : $85 / 15$. d) Solvent $/ \mathrm{H}_{2} \mathrm{O}: 75 / 25$

$\mathrm{NaOH}$ leads to the best yield (53\%, entry 3 ) and we also observed that adding more water was not suitable 
for the reaction ( $27 \%$, entry 4). Next the influence of the palladium source was evaluated, and $\operatorname{Pd}\left(\mathrm{PPh}_{3}\right)_{4}$ was used without showing an improvement (46\%, entry 5). The use of DavePhos as the ligand decreased dramatically the yield of the reaction (14\%, entry 6). THF was replaced by 1,4-dioxane or MeTHF, and did not show better results (44 and $34 \%$, entries 7-8). Eventually, the use of $\mathrm{Pd}(\mathrm{OAc})_{2} / \mathrm{PPh}_{3}$ with $\mathrm{NaOH}$ in a mixture of THF and water under microwave irradiation proved to be the conditions of choice to obtain $\mathbf{2 0}$ in good yield.

The scope and limitations of these optimized conditions were next investigated. The starting compound $\mathbf{1 b}$ was used with various aryl boronic acids $\left(\mathrm{Pd}(\mathrm{OAc})_{2}(5 \mathrm{~mol} \%), \mathrm{PPh}_{3}(10 \mathrm{~mol} \%), \mathrm{NaOH}(1.5\right.$ equiv.), THF $\left./ \mathrm{H}_{2} \mathrm{O}, \mathrm{MW}, 100{ }^{\circ} \mathrm{C}\right)$. The isolated yields for compounds 20-24 range from 15 to 53\% (Scheme 6 ). The presence of a donating group in meta-position of the aryl boronic acid hindered the reaction (15\% yield for 21 compared to $53 \%$ yield for $\mathbf{2 0}$ ). This was also the case with an electron withdrawing group in the para position ( $43 \%$ yield for 22 instead of $53 \%$ yield for 20) No reaction was observed with pentyl boronic acid.

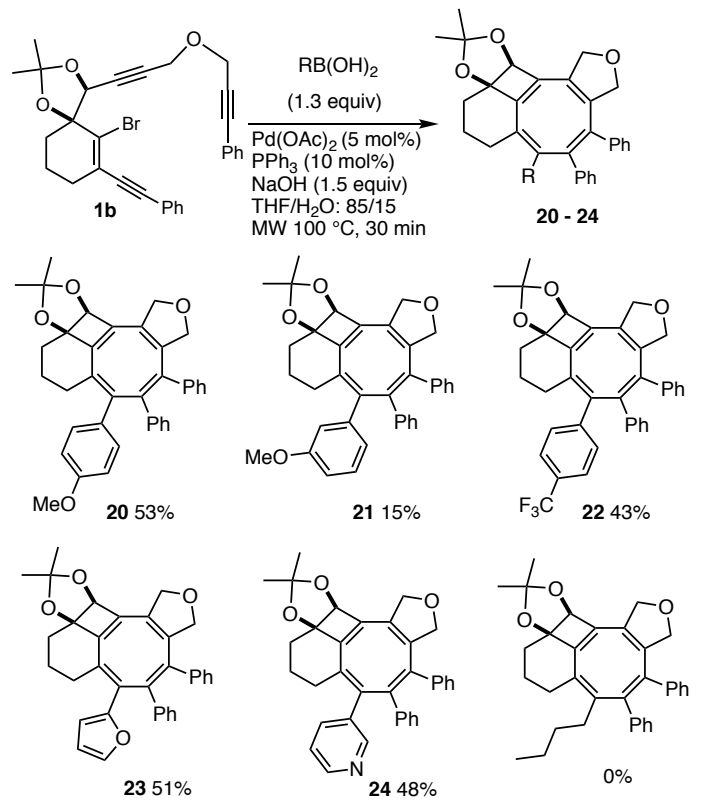

Scheme 6. Scope of the cascade reaction ended by a SuzukiMiyaura reaction.

Only one experiment was done with 1a to examine the Heck reaction as the terminating step in this palladium catalyzed reaction sequence. The use of methyl acrylate with $\mathrm{Pd}(\mathrm{OAc})_{2} / \mathrm{PPh}_{3}$ and diisopropylamine in benzene under microwave irradiation did not allow the formation of the cyclooctatetraene and only starting material 1a was isolated (Scheme 7).

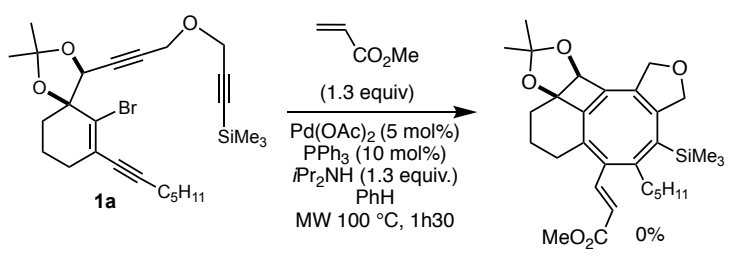

Scheme 7. Cascade reaction ended by a Heck reaction with methyl acrylate.

Structural modifications of the starting material were then investigated in order to study their effects on the course of the reaction and expand the structural diversity around the COT scaffolds. Indeed, the increase of the A, B and C ring sizes was studied as well as the introduction of a nitrogen atom in the ring C (Figure 1).

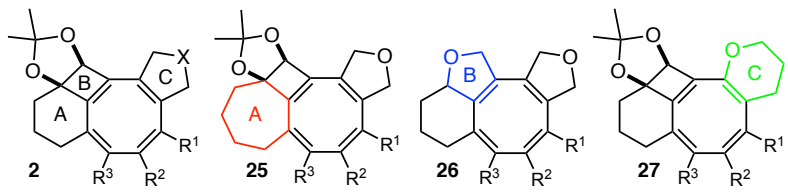

Figure 1. Structural modifications.

Compound 1c with a seven-membered ring instead of a six-membered ring was first synthesized and tested under the optimized conditions of both cascade reactions ended with Stille and Sonogashira crosscoupling (Scheme 8).

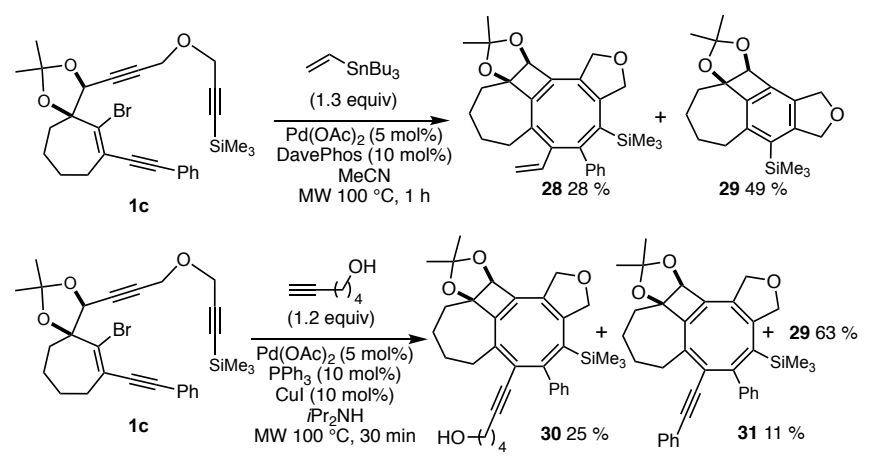

Scheme 8. Cascade reaction ended by Stille and Sonogashira cross coupling using a seven-membered ring precursor.

In both cases, cyclooctatetraenes $\mathbf{2 8}$ and $\mathbf{3 0}$ were isolated in modest yields (respectively 28 and $25 \%$ ) with the appreciable quantity of the aromatic side product 29 (49 and $63 \%$ ). This latter compound represents the major product of both reactions, showing a strong influence of the cycle $\mathrm{A}$ on the course of the reaction. Considering the mechanism, it indicates that a seven-membered A ring favorably promotes the $6 \pi$ electrocyclization from intermediate 
32 to 34 instead of the $8 \pi$ electrocyclization (Scheme 9).

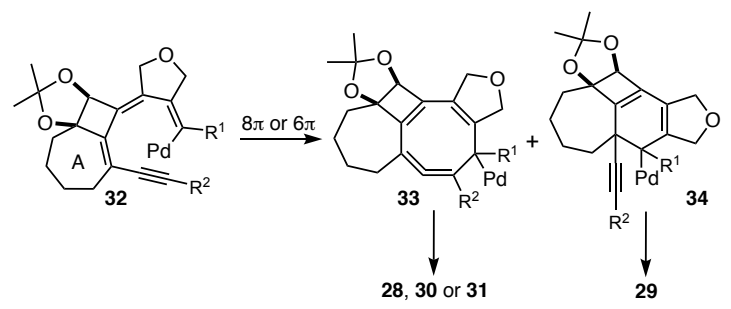

Scheme 9. Mechanistic consideration.

Next, the importance of the four-membered ring was evaluated and compound $\mathbf{3 5}$ was synthesized (Scheme 10). Various Stille or Sonogashira conditions ranging palladiums, ligands, base and solvents were examined in the synthesis of cyclooctatetraenes 36. None of them proved to be suitable for achieving high yields of the desired reaction. Indeed, compounds $\mathbf{3 6 a}$ or $\mathbf{3 6} \mathbf{b}$ seems to be present in poor yield (less than $30 \%$ ) in as a mixture of inseparable impurities and the reactions were not complete. No results were obtained with compound 38 containing an additional carbon on the side chain in order to increase the size of the cycle $\mathrm{C}$. Indeed, with Stille reaction conditions, starting material 38 was recovered without any traces of compounds 39 and $\mathbf{4 0}$. It is interesting to note that $\mathbf{4 0}$ was already synthetized by our group from a slightly different starting material missing the $\mathrm{C}_{5} \mathrm{H}_{11}$-alkyne side chain but by similar palladium catalyzed reaction conditions: twofold cyclocarbopalladations 4-exo- and 6-exo-dig followed by one $6 \pi$ electrocyclization. ${ }^{[8]}$ This non-reactivity of compound $\mathbf{3 8}$ may be due to a different conformation (less open) of the palladium species of type 9a (Scheme 10) after the formation of the six membered-ring by the 6-exo-dig carbopalladation when compared to the formation of the five membered-ring (Scheme 4, compound 9b). In the present case, this intermediate 9a shows strong streric interactions between palladium substituants, cyclohexene and $\mathrm{C}_{5} \mathrm{H}_{11}$-alkyne side chain that must prevent a possible final $8 \pi$ or $6 \pi$ electrocyclizations. It is not the case when the $\mathrm{C}_{5} \mathrm{H}_{11}$-alkyne side chain is not present in $\mathbf{3 8}$ leading easily to the aromatic compound 40.

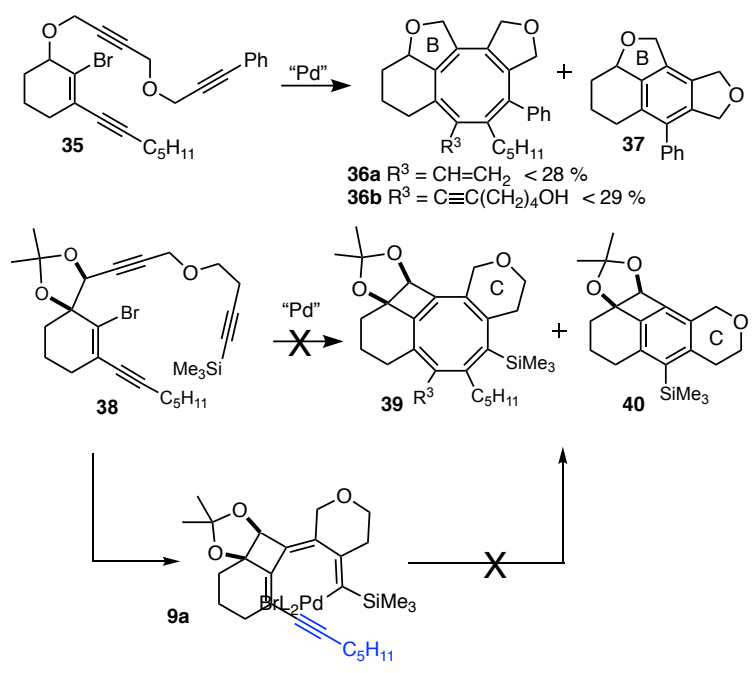

Scheme 10. B and $\mathrm{C}$ ring expansions.

The influence of the nitrogen atom on the structure was also studied (Scheme 11). Indeed, in previous work, with oxygen, we obtained COT 42a in $53 \%$ yield. Under the same reaction conditions, it was possible to isolate only $21 \%$ yield of the COT containing a BOC protected nitrogen atom $(\mathbf{4 2 c})$. The protection of the nitrogen was necessary because the reaction did not working with free amine (42b).

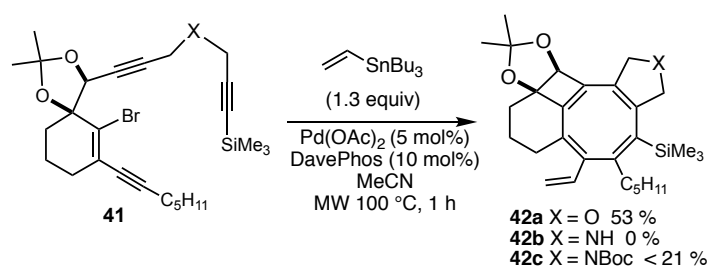

Scheme 11. Introduction of nitrogen atom.

\section{Conclusion}

In conclusion, we have proposed three routes for the formation of fully substituted cyclooctatetraenes: cyclocarbopalladations followed by an $8 \pi$ electrocyclization and ended either by Stille, Sonogashira or Suzuki-Miaura cross-couplings. Several new scaffolds containing alkynyl as well as substituted aryl and heteroaryl moieties has been obtained in good yields These new approaches present the advantage of extending the structural diversity of fully substituted unsymmetrical COT. The reactions proceeds in a one-pot operation, where three new rings and four bonds are formed.

\section{Experimental Section}

Cascade ended by a Sonogashira reaction. To an ovendried 0.5-2 mL microwave vial, under argon atmosphere, was loaded starting substrate $\mathbf{1 b}, \mathbf{1 c}$ or $\mathbf{3 5}(50 \mathrm{mg}, 0.1 \mathrm{mmol}$, 1 eq.) in diisopropylamine $(1 \mathrm{~mL}, 0.1 \mathrm{M})$. To this solution were added $\mathrm{Pd}(\mathrm{OAc})_{2}(1.1 \mathrm{mg}, 0.005 \mathrm{mmol}, 0.05$ eq. $)$, 
triphenylphosphine $(2.5 \mathrm{mg}, 0.01 \mathrm{mmol}, 0.1 \mathrm{eq}$.) and copper iodide ( $1.8 \mathrm{mg}, 0.01 \mathrm{mmol}, 0.1$ eq.). The vial was sealed with a teflon cap and the mixture was degassed by three cycles of freeze-pump-thaw. Finally, the alkynyl coupling partner (0.12 mmol, 1.2 eq.) was added. The reaction mixture was heated at $100^{\circ} \mathrm{C}$ under microwave irradiation for $30 \mathrm{~min}$. The reaction mixture was then filtered through a patch of celite and rinsed with $\mathrm{Et}_{2} \mathrm{O}$. After concentration of the mixture under reduced pressure, the crude material was purified by silica gel chromatography affording cyclooctatetraenes.

Cascade ended by a Suzuki-Miyaura reaction. To a $0.5-$ $2 \mathrm{~mL}$ microwave vial, under argon atmosphere, was loaded starting substrate $\mathbf{1 b}(50 \mathrm{mg}, 0.1 \mathrm{mmol}$, 1 eq.) in degassed anhydrous THF (1 mL, $0.1 \mathrm{M})$. To this solution were added $\mathrm{Pd}(\mathrm{OAc})_{2} \quad(1.1 \mathrm{mg}, \quad 0.005 \mathrm{mmol}, 0.05 \quad$ eq. $)$, triphenylphosphine $(2.5 \mathrm{mg}, 0.01 \mathrm{mmol}, 0.1 \mathrm{eq}$.$) , boronic$ acid coupling partner $(0.13 \mathrm{mmol}, 1.3 \mathrm{eq}$. $)$ and an aqueous $\mathrm{NaOH} 1 \mathrm{M}$ solution $(0.15 \mathrm{~mL}, 0.15 \mathrm{mmol}, 1.5 \mathrm{eq}$.). The vial was sealed with a teflon cap. The reaction mixture was heated at $100^{\circ} \mathrm{C}$ under microwave irradiation. The reaction mixture was then filtered through a patch of celite and rinsed with $\mathrm{Et}_{2} \mathrm{O}$. After concentration of the mixture under reduced pressure, the crude material was purified by silica gel chromatography affording cyclooctatetraenes.

Cascade ended by a Stille reaction. To an oven-dried 0.5 $2 \mathrm{~mL}$ microwave vial, under argon atmosphere, was loaded starting substrate $\mathbf{1 b}, \mathbf{1 c}, \mathbf{3 5}, \mathbf{3 8}$ or $\mathbf{4 1}(50 \mathrm{mg}, 0.1 \mathrm{mmol}, 1$ eq.) in acetonitrile $(1 \mathrm{~mL}, 0.1 \mathrm{M})$. To this solution were added $\mathrm{Pd}(\mathrm{OAc})_{2}(1.1 \mathrm{mg}, 0.005 \mathrm{mmol}, 0.05$ eq.), DavePhos (3.9 $\mathrm{mg}, 0.01 \mathrm{mmol}, 0.1 \mathrm{eq}$.) and finally the stannylated coupling partner $(0.13 \mathrm{mmol}, 1.3 \mathrm{eq}$. $)$. The mixture was purged with argon for 5 min before sealing the vial with a teflon cap. The reaction mixture was heated for $1 \mathrm{~h}$ at $100^{\circ} \mathrm{C}$ under microwave irradiation. The reaction mixture was then filtered through a patch of celite and rinsed with $\mathrm{Et}_{2} \mathrm{O}$. After concentration of the mixture under reduced pressure, the crude material was diluted in $1 \mathrm{~mL}$ of reagent grade $\mathrm{Et}_{2} \mathrm{O}$. To this solution was added DBU ( 1.5 eq.) followed by a 0.1 $\mathrm{M}$ ethereal iodine solution $(0.1 \mathrm{~mL})$. The mixture was then transferred to a short column of silica gel and eluted with $\mathrm{Et}_{2} \mathrm{O}$. Purification by flash chromatography on silica gel afforded cyclooctatetraenes.

\section{Acknowledgements}

The authors gratefully acknowledge the support of the University of Strasbourg Institute for Advanced Study (USIAS) and the MNERT (S.B.) for fellowship.

\section{References}

[1] a) M. J. Marsella, R. J. Reid, Macromolecules 1999, 32, 5982. b) R. Gleiter, B. Esser, S. C. Kornmayer, O. I. Universita, Acc. Chem. Res. 2009, 42, 1108. c) T. Nishiuchi, Y. Kuwatani, T. Nishinaga, M. Iyoda, Chem. Eur. J. 2009, 15, 6838. d) F. Schager, K. Haack, R. Mynott, A. Rufinska, K.-R. Pörschke, Organometallics 1998, 17, 807. e) P. W. Roesky, Eur. J. Inorg. Chem. 2001, 7, 1653. f) T. Murahashi, N. Kato, S. Ogoshi, H. Kurosawa, J. Organomet. Chem. 2008, 693, 894. g) T. Murahashi, S. Kimura, K. Takase, T. Uemura, S.
Ogoshi, K. Yamamoto, Chem. Commun. 2014, 50, 820. h) K. W. Glaeske, W. A. Donaldson, Mini. Rev. Org. Chem. 2012, 9, 31.

[2] B. C. Maiti, R. H. Thomson, M. Mahendran, J. Chem. Res. (M) 1978, 1682.

[3] a) W. Reppe, O. Schlichting, K. Klager, T. Toepel, Justus Liebigs Ann. Chem. 1948, 560, 1.

[4] a) Y. Yamamoto, T. Ohno and K. Itoh, Chem. - Eur. J., 2002, 8, 4734. b) X. Li, J.-W. Han and H. N. C. Wong, Asian J. Org. Chem., 2016, 5, 74. c) P. A. Wender, J. P. Christy, A. B. Lesser, M. T. Gieseler, Angew. Chem. Int. Ed. 2009, 48, 7687. d) K. Ouyang and Z. Xi, Chin. J. Catal., 2015, 36, 24. e) H. Zhang, J. Wei, F. Zhao, Y. Liang, Z. Wang and Z. Xi, Chem. Commun., 2010, 46, 7439. f) J. E. Perea-Buceta, T. Wirtanen, O. V. Laukkanen, M. K. Mäkelä, M. Nieger, M. Melchionna, N. Huittinen, J. A. Lopez-Sanchez, J. Helaja, Angew. Chem. Int. Ed. 2013, 52, 11835. g) K. Mouri, S. Saito, S. Yamaguchi, Angew. Chem. Int. Ed. 2012, 51, 5971. h) C. Wang, Z. Xi, Chem. Commun. 2007, 5119.

[5] For recent examples of cascade reactions including cyclocarbopalladations : a) J. Pétrignet, A. Boudhar, G. Blond, J. Suffert, Angew. Chem. Int. Ed. 2011, 50, 3285. b) C. Hulot, G. Blond, J. Suffert, J. Am. Chem. Soc. 2008, 130, 5046. c) M. Charpenay, A. Boudhar, G. Blond, J. Suffert, Angew. Chem. Int. Ed. 2012, 51, 4379. d) C. Hulot, S. Amiri, G. Blond, P. Schreiner, J. Suffert, J. Am. Chem. Soc. 2009, 131, 13387. e) M. Charpenay, A. Boudhar, C. Hulot, G. Blond, J. Suffert, Tetrahedron 2013, 69, 7568. f) J. Joussot, A. Schoenfelder, J. Suffert, G. Blond, Comptes Rendus Chim., 2017, 20, 665. g) N. Ghosh, C. Maiereanu, J. Suffert and G. Blond, Synlett, 2016, 28, 451. h) M. Charpenay, A. Boudhar, A. Siby, S. Schigand, G. Blond, J. Suffert, Adv. Synth. Catal., 2011, 353, 3151. i) T. Castanheiro, M. Donnard, M. Gulea, J. Suffert, Org. Lett., 2014, 16, 3060. j) P. Wagner, M. Gulea, J. Suffert, M. Donnard, Chem. - Eur. J., 2017, 23, 7458. k) A. Düfert, D. B. Werz, Chem. Eur. J., 2016, 22, 16718. 1) X. Zhang, H. Liu, Y. Jia, Chem. Commun., 2016, 52, 7665-7667. m) L. F. Tietze, B. Waldecker, D. Ganapathy, C. Eichhorst, T. Lenzer, K. Oum, S. O. Reichmann, D. Stalke, Angew. Chem. Int. Ed., 2015, 54, 10317-10321. n) B. Milde, M. Leibeling, M. Pawliczek, J. Grunenberg, P. G. Jones, D. B. Werz, Angew. Chem. Int. Ed., 2015, 54, 1331-1335

[6] S. Blouin, V. Gandon, G. Blond, J. Suffert, Angew. Chem. Int. Ed., 2016, 55, 7208.

[7] C. Amatore, G. Le Duc, A. Jutand, Chem. Eur. J. 2013, 19, 10082.

[8] G. Blond, C. Bour, B. Salem and J. Suffert, Org. Lett., 2008, 10, 1075. 
